\title{
O consumidor esportivo e o Novo Basquete Brasil: análise do perfil do torcedor nas finais Bauru x Paulistano em 2017
}

https://doi.org/10.11606/issn.1981-4690.v35i3p51-65

\section{Resumo}

Oobjetivo do estudo éanalisar as conexões entre o basquete e o perfil de torcedores que compareceram aos dois últimos jogos das finais da nona edição do Novo Basquete Brasil (NBB), em 2017. A pesquisa tem natureza qualitativa, e o percurso metodológico valeu-se da aplicação aleatória de um questionário com 39 perguntas junto aos torcedores presentes nos ginásios, ou no seu entorno, momentos antes dos jogos, disputadosemjunhode 2017,nascidades deSãoPauloeAraraquara.A partirdaanálisede 91 questionários e da observação das ações de patrocínio, foi realizada uma entrevista semiestruturada com o Gerente de Comunicação da Liga Nacional de Basquete (LNB). Os resultados indicam a predominância de um público masculino, jovem e de alto poder aquisitivo nos dois jogos ( $57 \%$ dos respondentes têm renda familiar mensal acima de $\mathrm{R} \$ 4,5 \mathrm{mil}$ ). Esses torcedores apresentam um envolvimento afetivo com o basquete e com os times, porém não têm uma relação formal ou monetária com as equipes. A comunicação via mídias sociais atinge boa parcela desse público, que aprova ações de entretenimento duranteo evento esportivo. Portanto, há um potencial para estreitar o relacionamento com os torcedores. $O$ trabalho desenvolvido há dez anos pela LNB tem gerado parcerias com empresas e grandes grupos de comunicação, além da adoção de práticas bem-sucedidas no exteriorna gestão esportiva. Em 2014, a Liga anunciou uma parceria inovadora edelongo prazo coma National Basketball Association(NBA). Há obstáculosa serem superados, principalmente na administração dos clubes, e este artigo espera contribuir para a melhoria do processo.

Palavras-Chave: Comunicação; Gestão do Esporte; Marketing; NBB; Liga Nacional de Basquete.

\section{Introdução}

A indústria do esporte ainda é inexpressiva e incipiente no Brasil. Os dirigentes de clubes, federaçôes e confederações, de praticamente todas as modalidades, não perceberam que o ambiente de negócios do esporte mudou drasticamente nas últimas duas décadas. A imensa maioria das entidades esportivas nacionais segue o modelo de associações privadas sem fins lucrativos, sistema que favorece a gestão amadora e pouco profissional. Para a melhoria esportiva e econômica dessas entidades, é necessário discutir de forma contundente, na academia e no mercado, alteraçóes nesse modelo, tipicamente brasileiro, sinônimo de má gestão e de corrupção no esporte ${ }^{1}$.
Embora não seja uma ruptura com essa estrutura, a Liga Nacional de Basquete (LNB), uma associação civil de direito privado, de fins não econômicos, reconhecida pela Confederação Brasileira de Basketball $(\mathrm{CBB})^{2}$, tem se destacado no ambiente esportivo por suas práticas de gestão e de comunicação, chanceladas pela National Basketball Association (NBA), principal entidade do basquete norte-americano, o mais competitivo esportiva e economicamente em todo o mundo.

A LNB completou em $2018 \mathrm{dez}$ anos de existência. Formada a partir da união de clubes brasileiros de basquete, foi constituída para organizar o Novo Basquete Brasil (NBB), o
${ }^{*}$ Centro Universitário das Faculdades Metropolitanas Unidas,São Paulo, SP, Brasil.

**Escola de Educação Física e Esporte, Universidade de São Paulo, São Paulo, SP, Brasil. 
campeonato brasileiro na categoria masculina. Malagrino ${ }^{3}$ recorre a Dietl et al. ${ }^{4}$ para comentar que ligas de clubes tiveram origem nos esportes norte-americanos e começaram a se tornar consenso mundial, atingindo também modalidades na Europa. Neste modelo de governança cooperativa, os clubes seguem autônomos nas suas decisóes individuais e, como proprietários da liga, passam a atuar coletivamente na organizaçáo do campeonato, pois um clube forte precisa de adversários fortes para o desenvolvimento de um produto comercializável.

A LNB conquistou parceiros e se tornou a primeira entidade esportiva no Brasil a fechar parceria com o Facebook, para transmissóes de jogos via streaming. Em 2017, concretizou-se parceria com o Twitter ${ }^{5}$. Açôes inovadoras, para o mercado esportivo brasileiro, estão sendo adotadas para entreter a audiência, fragmentada em TV aberta, TV fechada, sites e mídias sociais. De acordo com o IBOPE Repucom, empresa líder em pesquisa de marketing esportivo e patrocínio no Brasil, o retorno dos investimentos feitos pelos patrocinadores pode ser mensurado, por exemplo, pelas 330 horas de exposição na mídia durante a temporada 2016/17, com 246,8 mil apariçóes dos patrocinadores, o equivalente a R \$ 2,9 bilhóes em espaço ocupado na mídias.

Esse processo de profissionalização da gestão e da comunicação realizado pela LNB, a partir de práticas bem-sucedidas na NBA e em parceria com grandes empresas de comunicação (Facebook, Twitter e Grupo Globo), justifica a realização deste estudo. Trata-se de um tema ainda pouco analisado academicamente, e é importante fomentar discussóes para um melhor entendimento sobre a Gestão do Esporte, fundamental para o desenvolvimento do esporte no Brasil. O públicoalvo são estudantes de Educação Física, Esporte e Administração (além de outras possíveis áreas afins), gestores, coordenadores e diferentes atuantes nas organizaçóes esportivas existentes no país ${ }^{1}$.

A mudança de cenário do consumo esportivo é mais uma justificativa. A literatura apresenta estudos sobre os fatores que afetam a presença do torcedor em eventos esportivos, tais como a qualidade técnica da disputa, preço do ingresso, facilidade de acesso ao local, segurança, entretenimento, a relação afetiva com a modalidade, com o time e com os atletas. Entender esses fatores é essencial para o desenvolvimento de estratégias e processos para atingir o objetivo chave de aumentar a participação do torcedor ${ }^{6}$.

MALAGRINO $^{3}$ cita James para refletir sobre as constantes mudanças nos hábitos dos consumidores e como o uso da internet e das mídias sociais exige que as empresas repensem seu ambiente de negócios, também na esfera esportiva. Segundo Malagrino ${ }^{3}$

[...] os times e equipes esportivas devem assumir uma visão na qual o torcedor seja visto como alguém que contribui significativamente para o valor do produto/serviço e que, ao mesmo tempo, direciona as estratégias da organização. Assim, os times devem buscar estratégias para aumentar o envolvimento ativo dos torcedores com o time e com as empresas patrocinadoras, incentivando-os a ser embaixadores da marca (p. 32) ${ }^{3}$.

O desenvolvimento e manutenção de um grupo apaixonado de fãs é vital para o sucesso de equipes e modalidades esportivas ${ }^{7}$ e os fâs, de forma geral, não podem ser considerados clientes típicos $^{8}$. Os fấs não se limitam a assistir e comprar, mas são devotos entusiastas de uma equipe e/ou modalidade esportiva9 ${ }^{9}$. Revelam forte senso de identificação com suas equipes e modalidades e, comumente, expressam isso através das cores que usam ou pelas histórias e tradições que reproduzem da equipe com a qual se identificam ${ }^{10-12}$.

Além disso, pesquisas sugerem que indivíduos altamente engajados, como os fấs de uma equipe ou modalidade esportiva, exibem altos níveis de participação, recomendam a equipe ou a modalidade para outras pessoas e compram mais mercadorias e produtos ${ }^{13,14}$. O engajamento do consumidor no contexto do esporte adquiriu nova dimensão com o desenvolvimento das novas mídias, o que afetou sobremaneira a forma como as organizações esportivas se comunicam e divulgam produtos e serviços para seus torcedores ${ }^{15}$.

A partir de estudos sobre os fatores que afetam a presença do torcedor em eventos esportivos, o objetivo deste artigo é descrever, com base em pesquisa de campo, o perfil de quem frequentou os ginásios para assistir às finais da $9^{a}$ edição do NBB, na temporada de 2016-17. Esta pesquisa buscou classificar, de acordo com as teorias de Rein, Kotler e Shields ${ }^{15}$, o nível de lealdade desses torcedores que foram aos ginásios assistir 
a dois jogos das finais do NBB em 2017, além de identificar qual o ponto de conexão desses entrevistados com o NBB e os dois clubes finalistas.

$\mathrm{O}$ esporte é um meio de comunicação para o consumo, e os patrocinadores buscam um retorno quando investem em competiçóes, equipes e atletas. Os gestores têm como desafio aumentar o comprometimento dos torcedores e o consumo do seu produto esportivo e, para isso, precisam compreender os conectores nessa relação do público com o basquete, as equipes e o NBB. Pretendemos neste estudo contribuir para um melhor conhecimento do perfil do atual consumidor do produto basquete brasileiro masculino de clubes e, consequentemente, colaborar para o aperfeiçoamento e modernização da gestão do esporte profissional no Brasil.

\section{Método}

Para a efetivação desta pesquisa, de natureza qualitativa, foram entrevistadas 91 pessoas que compareceram a dois jogos da fase final dos playoffs do NBB, em junho de 2017, no estado de São Paulo. A escolha desses dois jogos se deve à importância do evento para o NBB, por terem decidido o campeonato de 2017 e atraído a atençáo da mídia e dos torcedores. Em geral, quando comparado com os jogos da fase regular da competição, os playoffs, por seu caráter decisivo, atraem um número maior de fầs e adeptos do basquete.

O primeiro passo foi elaborar um instrumento com 39 perguntas para aplicá-lo, aleatoriamente, junto a torcedores presentes nos dois jogos. As questóes objetivavam identificar: o perfil do torcedor/ consumidor presente nas partidas finais do NBB em 2017 e, principalmente, sua relação e conexôes com o produto basquete masculino de clubes.

Em sua nona edição, na temporada 2016/17, o NBB teve como finalistas dois times paulistas: o Bauru Basket e o Paulistano/Corpore. A competição foi decidida numa série de cinco confrontos e os questionários foram aplicados nos dois últimos jogos: no dia 10 de junho de 2017, no ginásio do Parque Sáo Jorge, na zona leste da cidade de São Paulo, tendo o Paulistano como mandante; e em 17 de junho de 2017, no ginásio Gigantão, em Araraquara, onde o Bauru foi o anfitrião. A abordagem aos torcedores ocorreu dentro do ginásio e no entorno, antes das partidas. $\mathrm{O}$ preenchimento demorou, em média, 5 minutos, e 91 questionários foram obtidos para a análise do perfil do público presente nos dois ginásios (30 na cidade de São Paulo e 61 em Araraquara).

Todos os respondentes assinaram o termo de consentimento, em que o anonimato estava garantido pelos pesquisadores. Nesse termo consta que o questionário seria respondido por livre e espontânea vontade e com previsão de desistência a qualquer momento por parte dos respondentes, sem prejuízos para eles. Como o estudo foi desenvolvido em uma disciplina realizada no campo da Comunicação, a pesquisa náo foi enviada ao Comitê de Ética, prerrogativa não exigida pela área para pesquisas dessa natureza. Importante salientar que, ao contrário de práticas de laboratório com humanos e animais, as pesquisas realizadas em eventos com torcedores têm sua segurança, e de todos os frequentadores, garantidas pelo Estatuto de Defesa do Torcedor ${ }^{16}$, que em seu artigo 14 afirma que "a responsabilidade pela segurança do torcedor em evento esportivo é da entidade de prática desportiva detentora do mando de jogo e de seus dirigentes". Os respondentes não foram ao ginásio exclusivamente para responder ao questionário, mas para assistir ao evento foco da pesquisa.

Esta pesquisa foi desenvolvida durante a disciplina de Metodologia de Pesquisa Aplicada à Administração I, na Faculdade de Economia, Administraçáo e Contabilidade, da Universidade de São Paulo (FEA-USP). A proposta da docente responsável pela disciplina foi de, no trabalho de conclusão, iniciar a pesquisa desde sua concepção, a partir de um problema real, até a apresentaçáo final, passando, inclusive, pela construção do instrumento (questionário). Portanto, trata-se de um instrumento inédito, construído a partir de uma teoria já consolidada (as teorias de ReIn, Kotler e SHIElds ${ }^{15}$ ) e validado internamente.

Como base teórica para sustentação desta pesquisa e elaboração do instrumento, foram utilizados os pontos de ligaçẫo (conectores) com os fẫs/consumidores ${ }^{15}$, além de conceitos de gestão e comunicaçáo esportiva. Os pontos de contato que ligam os torcedores/ consumidores ao esporte estão distribuídos em três grandes grupos de conectores: conectores fundamentais (astro e local), conectores de comunicação social (moeda social e família) e conectores de busca 
(experiência indireta, incerteza e utopia). Dentro desses três grandes grupos subdividem-se os outros conectores: Astro (alguém ou algo que tem potencial de atração para conectar-se com o fã para o esporte por meio de suas açóes, personalidade ou capacidade técnica); Local (capitalizam a presença de equipes, atletas e instalaçôes e predispóem os torcedores a apoiar esportes que sejam de sua área ou que representem sua comunidade); Moeda social (esporte como elemento de ligação entre grupos de amigos, comunidades e outras relaçóes, cuja informação compartilhada mantém e incentiva a relação social; Família (esporte como fator de união, pois ajuda a manter tradiçóes e valores familiares e estabelecer conexôes com parentes afastados); Experiência Indireta (vínculo com o esporte através da identificação, admiração ou imitação das habilidades e desempenho de atletas); Incerteza (imprevisibilidade, espontaneidade e tentativa de prever resultados que proporcionam um escape à monotonia do dia-a-dia); Utopia (representação do passado e recordaçóes que recriam determinados esportes $)^{15}$. Após a identificação e classificação dos seus torcedores/consumidores, utilizando os conectores, uma organização esportiva pode construir estratégias de comunicação e marketing direcionadas a atingir seus objetivos.

Com base nos conectores, foram redigidas 32 afirmaçôes em escala Likert, de 1 a 5 (1-Discordo Totalmente, 2-Discordo, 3-Não concordo/Não Discordo, 4-Concordo e 5-Concordo Totalmente), e mais sete perguntas sobre faixa etária, sexo, renda mensal familiar, nível de escolaridade, meio de transporte para ir ao ginásio, local onde mora e com que frequência pratica basquete. $\mathrm{O}$ método de estática descritiva ${ }^{17}$ foi utilizado para analisar os 91 questionários.

A segunda etapa da pesquisa foi uma entrevista presencial com Guilherme Buso, Gerente de Comunicação da LNB, baseada em instrumento com roteiro semiestruturado. As perguntas foram elaboradas a partir da análise qualitativa dos dados obtidos nos questionários, além do trabalho desenvolvido pela Liga e da parceria com a NBA. A análise dos dados obtidos nessa entrevista com o porta-voz da LNB foi realizada por meio do processo de codificação e categorização das informações com base em temas ${ }^{18-19}$. As categorias são grupos compostos por unidades de registro/códigos com características comuns que podem ser baseadas em critérios semânticos, sintáticos, léxicos ou expressivos $^{20-21}$. Nesta pesquisa, adotamos critérios semânticos. A definição das categorias foi realizada a priori, a partir dos objetivos da pesquisa e das informaçóes obtidas na fundamentação teórica, com base nos resultados obtidos da análise dos questionários. Os temas pré-estabelecidos foram: fidelização do torcedor; parceria com a NBA; comercialização de produtos licenciados; açóes de entretenimento durante os jogos; comunicação via mídias sociais; a importância do astro.

\section{Referencial teórico}

A partir da leitura de Barthes ${ }^{22}$, em O que é Esporte?, CAMPOS e Rocco Júnior (p. 126) ${ }^{23}$ abordam o esporte como um instrumento de comunicação. "Esporte tem tudo a ver com comunicação. É comunicação".

O pensador francês do século XX analisa a prática esportiva, principalmente de alto rendimento, como ocupante, na sociedade contemporânea, de um espaço que outrora fora do teatro. É uma forma de conectar as pessoas socialmente. De acordo com BARTHEs (p. 104) ${ }^{22}$.

Em determinadas épocas, em determinadas sociedades, o teatro teve uma grande função social, reunindo a cidade inteira numa experiência comum: o conhecimento de suas próprias paixóes. Hoje é o esporte que, à sua maneira, exerce essa função. (...) o esporte é uma grande instituição moderna baseada nas formas ancestrais do espetáculo ${ }^{22}$.

Nas arenas esportivas, os competidores são os astros principais, assim como os atores são os protagonistas no teatro. Para além das arenas, o esporte se comunica com o espectador que não está nos locais de disputa. Nos megaeventos esportivos o espetáculo é produzido duas vezes. A primeira dimensão comunicacional envolve quem compartilha in loco o ritual (atletas, treinadores, juízes, organizadores, espectadores etc.), ou seja, quem está no espaço e no tempo da realização da disputa. A segunda dimensão comunicacional é voltada aos ausentes da arena esportiva, que assistem a uma representação do que lá ocorre. Eles não veem o que de fato está acontecendo e acreditam estar vendo o real por meio de uma interface midiática ${ }^{24}$.

CAmpos e Rocco Júnior (p. 31) ${ }^{23}$ afirmam que, no mundo esportivo midiatizado e de comunicação em larga escala, "estudar a comunicação esportiva é fundamental para se entender o esporte e, por consequência, para se posicionar de maneira mais efetiva na gestão esportiva atual”. Em diálogo com outros teóricos, os pesquisadores pontuam que o 
esporte vive sua fase pós-moderna, com a crescente participação de empresas, patrocinadores, jornalistas e fắs na construção de marcas cada vez mais fortes ${ }^{23}$. No contexto desta pesquisa, acrescentamos que os dirigentes de clubes e de ligas devem primar por estratégias adequadas de comunicação que identifiquem plenamente marcas interessadas em se associar ao esporte.

O desenvolvimento da tecnologia digital modifica as formas de comunicação típicas da modernidade, e a participação dos făs atinge níveis elevados. Professor de Ciências Humanas e fundador do programa de Estudos de Mídia Comparada do MIT (Massachusetts Institute of Technology), Henry Jenkins (p. 29) 25 estuda a “[...] cultura da convergência, onde as velhas e as novas mídias colidem, onde mídia corporativa e mídia alternativa se cruzam, onde o poder do produtor de mídia e o poder do consumidor interagem de maneiras imprevisíveis".

Atualmente, as organizaçóes, por meio das redes sociais, competem pela atençáo dos consumidores, com o objetivo de impulsionar o seu envolvimento ${ }^{26-27}$. Também por intermédio destes canais, questóes como a comunicação em dois sentidos (e.g., resposta às publicaçôes por meio de opinióes e comentários) e a partilha de informação tendem a potenciar a geração de conhecimento e interesse dos consumidores, com base na propagação quase instantânea das suas experiências com a organização e com as suas marcas, produtos e/ou serviços ${ }^{28}$. No contexto atual das organizaçóes esportivas, sites e blogs da Internet parecem ter influenciado de maneira significativa os fấs que se informam sobre marcas de entidades esportivas e a percepção que tais torcedores constroem sobre essas marcas ${ }^{29}$.

Dentro da indústria do esporte, a comunicação deve ser planejada para atingir os mais variados stakeholders. A comunicação institucional é um ativo valioso, e conceitos como transparência, ética e responsabilidade social se tornam essencial para o negócio. Campos e Rocco Júnior (p. 132) ${ }^{23}$ pontuam que

O marketing, ferramenta de gestão surgida no auge da modernidade, calcada nos meios tradicionais de comunicação de massa, perde, assim, espaço para a comunicação, amplamente integrada na imensa profusão de novas formas de comunicação midiática. A relação um-todos típica da "Era do Marketing" dá lugar à relação todos-todos que, para melhor aproveitamento mercadológico, demanda o desenvolvimento de estratégias mais adequadas da "Era da Comunicação"23.

Um dos maiores desafios das organizaçóes é gerenciar a forma como interagem com os consumidores $^{30}$. As relaçóes entre as pessoas e as marcas são análogas às relaçóes interpessoais ${ }^{31}$. Isso porque os sentimentos envolvidos em ambos os casos são semelhantes - e.g., a atração, o prazer, o apego, a segurança, a estabilidade ou a autoestima ${ }^{32}$ e influenciam diretamente o valor atribuído ao relacionamento. Dessa forma, a qualidade da relação organizaçâo-consumidor representa uma oportunidade para a organizaçáo ${ }^{33}$, na medida em que cria um conjunto de conexóes, permite sinergias únicas e desperta o envolvimento ${ }^{34-35}$.

Quando o consumidor avalia como positiva a sua relação com a marca, com o produto ou serviço, há maior probabilidade de criação de um vínculo e, se for forte o suficiente, tende a determinar os seus comportamentos e açóes em relação à organização e.g., um nível ótimo da relação do consumidor com a marca pode até fazê-lo mudar de loja, ou adiar a sua compra, quando não consegue encontrar sua marca desejada $^{36-38}$. Esse cenário ratifica a necessidade de a organizaçáo conhecer bem o seu consumidor e darlhe aquilo que ele espera, porque boas impressóes do consumidor em relação ao que recebe da organização, em termos de experiências com a marca, produto ou serviço, tendem a aproximá-lo cada vez mais ${ }^{39}$. A relação da organização com o consumidor é um meio de criar, aumentar e manter interaçóes, para potenciar suas atitudes e comportamentos, com o objetivo de estender essa relaçáo por um longo período de tempo ${ }^{40}$.

Rein, Kotler e Shields ${ }^{15}$ constataram que "o primeiro passo decisivo para identificar, atrair e manter torcedores depende de entender não apenas o que esse fâ representa, mas igualmente como é que ele se conecta a um esporte” (p. 66) ${ }^{15}$. É preciso compreender que os torcedores não são simplesmente comprometidos. Eles também precisam tomar decisões, fazer escolhas com orçamentos limitados e são altamente conquistáveis se estimulados adequadamente ${ }^{15}$. Os autores trabalham com o conceito de "conectores fundamentais", ou seja, os pontos de contato que ligam os torcedores ao esporte e afirmam que as conexôes de lugar predispóem os torcedores a apoiar esportes que representem sua região. Ressaltam também a importância de se conhecer a área em que um determinado esporte está sendo praticado e quem são seus fãs, para uma 
comunicação efetiva.

Essas conexôes têm fundamento na necessidade sentida pelos torcedores de interação comunitária, filiação e ligação com seu lugar de residência atual ou anteriores. Em muitos casos, um aspecto chave da identidade do lugar é relacionado com as equipes de esportes que representam a comunidade (p. 69) $)^{15}$.

No Brasil, é consenso na academia e entre jornalistas especializados que a gestão esportiva está muito atrasada, em comparação ao profissionalismo do esporte em países do primeiro mundo. O desenvolvimento do esporte de alto rendimento depende de aspectos referentes ao treinamento esportivo (anos de treinamento e qualidade do treinador), às condiçóes psico e socioeconômicas (apoio familiar e profissional e condições financeiras para treinar) e ao sistema organizacional do esporte na sociedade (nacional e regional) e especificamente da modalidade esportiva, de acordo com VAN $\operatorname{Rossum}^{a}$ (2004 apud Meira, Bastos e BöHme ${ }^{41}$ ).

A estrutura organizacional voltada ao desenvolvimento das modalidades esportivas é objeto de estudos em diversos países. MeIra, Bastos e BöHME ${ }^{41}$ afirmam que essas pesquisas buscam o entendimento dos vários aspectos que envolvem os sistemas esportivos dos países.

Os resultados desses estudos apontam que é possível identificar particularidades de acordo com cada país, como também, açôes semelhantes entre eles, indicando a existência de pontos comuns relevantes no desenvolvimento do esporte de alto nível que devem ser destacados e valorizados (p. 251) ${ }^{41}$.

A Lei no 9.615, conhecida como Lei Pelé, possibilita a existência de ligas regionais e nacionais, de direito privado, com ou sem fins lucrativos, encarregadas da coordenação, administração, normatização, apoio e prática do desporto ${ }^{42}$.
Entretanto, a criação de ligas independentes de clubes ainda é uma prática incomum no Brasil, onde as confederações nacionais e federações estaduais controlam os clubes e são responsáveis por organizar as competiçóes. Nessas entidades, são frequentes os casos de corrupçáo no uso de dinheiro público - responsável por financiar $98 \%$ do esporte olímpico nacional nos anos que antecederam os Jogos Olímpicos do Rio-2016, segundo o Tribunal de Contas da Uniáo ${ }^{43}$ - e dirigentes que se perpetuam no poder, por meio de eleiçóes com chapas únicas (há confederaçóes comandadas pelo mesmo presidente há quase três décadas).

$\mathrm{Na}$ Europa e nos Estados Unidos, as ligas independentes de clubes são cases de sucesso. $\mathrm{Na}$ Inglaterra, a Premier League foi fundada em 1992 e os times de futebol alteraram o seu modelo de gestão. Em 2017, seis clubes ingleses aparecem entre as 10 marcas mais valiosas do futebol mundial, de acordo com a consultoria inglesa Brand Finance ${ }^{44}$. O Manchester United ${ }^{\mathrm{b}}$, da Inglaterra, lidera o ranking e sua marca está avaliada em 1,7 bilhão de dólares (um crescimento de $48 \%$ em relação a 2016). Completam o top 10: Real Madrid (Espanha), Barcelona (Espanha), Chelsea (Inglaterra), Bayern de Munique (Alemanha), Manchester City (Inglaterra), PSG (França), Arsenal (Inglaterra), Liverpool (Inglaterra) e Tottenham (Inglaterra).

Em 2015, o Brasil estava representado por dois times no ranking das 50 mais valiosas marcas do futebol mundial ${ }^{45}$ - São Paulo Futebol Clube, em 43ㅇ, e Sport Club Corinthians Paulista, em 48․ Em $2016^{46}$ e $2017^{44}$, nenhum clube brasileiro constava no ranking, composto por 50 times europeus. É um indicativo de que os clubes brasileiros de futebol, apesar de a modalidade ser a mais popular no país, precisam evoluir em termos de gestáo. E o que acontece na gestão do futebol brasileiro repercute, de forma ainda mais drástica, nas demais modalidades do país, carentes da estrutura e dos recursos financeiros destinados à modalidade esportiva mais importante do Brasil.

\section{Resultados}

De acordo com o levantamento realizado nesta pesquisa, as duas partidas finais do NBB 2016/17 foram frequentadas por um público jovem: 38 pessoas $(41,7 \%)$ disseram ter entre 18 e 24 anos e 23 assinalaram $(25,3 \%)$ a opção entre 25 e 34 anos. Portanto, $67,0 \%$ dos respondentes têm no máximo 34 anos. As alternativas que representam faixa etária igual ou superior a 35 anos somaram 29 respostas (31,9\%). Em relação ao local, 24 (26,4\%) pessoas disseram que moram na capital paulista, enquanto $53(58,2 \%)$ vivem em outras cidades do estado de São Paulo e 14 (15,4\%) vivem em 
outros estados do Brasil. O estudo aponta que 56 respondentes eram homens e 33 mulheres (dois não responderam).

Foram aos ginásios torcedores de alto poder aquisitivo, em comparação com a média nacional: 52 pessoas $(57,1 \%$ do total) disseram ter uma renda familiar mensal superior a $\mathrm{R} \$ 4,5$ mil, sendo que $20(22,0 \%)$ declararam estar na faixa acima de R\$ 9 mil mensais (FIGURA 1). Em 2016, o rendimento nominal mensal domiciliar per capita da população brasileira foi de $R$ \$ 1.226, calculado com base nas informaçóes da Pesquisa Nacional por Amostra de Domicílios
Contínua (PNAD Contínua) ${ }^{47}$.

Em relação à prática da modalidade, 42 $(46,1 \%)$ torcedores dizem que não jogam basquete e $14(15,4 \%)$ afirmam que nunca jogaram - 61,5\% dos respondentes têm uma relação com a modalidade somente como espectador -, enquanto 35 (38,5\%) são praticantes (30 jogam basquete há mais de um ano, e 5 há menos de um ano).

Após essa análise demográfica, a nossa proposta foi a de avaliar qual a relação desses torcedores com o basquete, com o NBB, com os times e com o evento esportivo (TABELA 1).

FIGURA 1 - Renda mensal familiar dos respondentes.

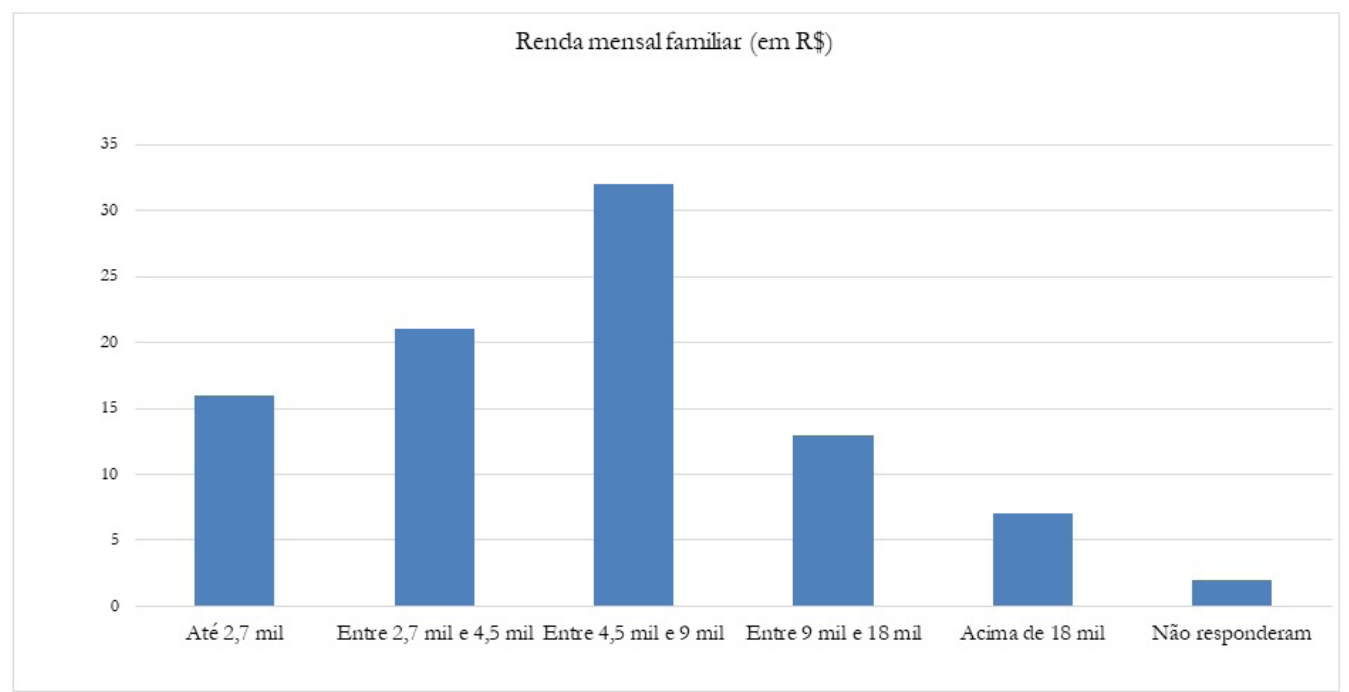


TABELA 1 - Conectores.

\begin{tabular}{|c|c|c|c|c|}
\hline & Mínimo & Máxima & Média & DP \\
\hline Torço para um time da NBB e sempre vou ao ginásio para vê-lo jogar. & 1 & 5 & 3,61 & 1,36 \\
\hline Acompanho meu time da NBB nas redes sociais. & 1 & 5 & 4,00 & 1,33 \\
\hline Acompanho mais meu ídolo no basquete do que um time da NBB. & 1 & 5 & 2,47 & 1,30 \\
\hline Passei a acompanhar o basquete nacional após a NBB ser criada, em 2008. & 1 & 5 & 3,02 & 1,46 \\
\hline Vou aos jogos apenas na fase decisiva da NBB. & 1 & 5 & 2,35 & 1,31 \\
\hline Acompanho mais NBA do que NBB. & 1 & 5 & 2,8 & 1,36 \\
\hline Acompanho NBA e gosto de basquete. Por isso, passei a ver os jogos da NBB. & 1 & 5 & 3,32 & 1,30 \\
\hline Sempre assisto aos jogos da NBA pela Internet. & 1 & 5 & 2,79 & 1,43 \\
\hline Vou ao ginásio pela proximidade com a minha casa. & 1 & 5 & 2,5 & 1,44 \\
\hline Vou ao ginásio pela atmosfera criada pelo evento esportivo. & 1 & 5 & 3,64 & 1,29 \\
\hline Gosto de participar de eventos esportivos (qualquer modalidade) na minha cidade & 1 & 5 & 3,83 & 1,20 \\
\hline $\begin{array}{l}\text { Tenho acesso aos locais restritos para imprensa e organizadores, como os vestiários } \\
\text { e a quadra. }\end{array}$ & 1 & 5 & 2,04 & 1,27 \\
\hline Assisto aos jogos de qualquer time da NBB pela TV, porque gosto de basquete. & 1 & 5 & 3,51 & 1,29 \\
\hline Participo de torcida organizada do meu time de basquete. & 1 & 5 & 1,72 & 1,09 \\
\hline $\begin{array}{l}\text { Contribuo com doaçóes, incentivos fiscais, incentivos financeiros, materiais etc., } \\
\text { para o meu time de basquete. }\end{array}$ & 1 & 5 & 1,91 & 1,21 \\
\hline Sempre participo de atividades ligadas a um fấ-clube do meu time de basquete. & 1 & 5 & 2,01 & 1,18 \\
\hline Participo de grupos de redes sociais relacionados ao meu time de basquete. & 1 & 5 & 3,24 & 1,48 \\
\hline Costumo assistir aos jogos do meu time de basquete com meus amigos. & 1 & 5 & 4,10 & 1,04 \\
\hline $\begin{array}{l}\text { Sempre acompanho os jogos do meu time de basquete nos canais de mídia (TV, } \\
\text { Internet). }\end{array}$ & 1 & 5 & 3,96 & 1,11 \\
\hline $\begin{array}{l}\text { Deixo de comparecer a programas familiares para assistir aos jogos do meu time do } \\
\text { NBB no ginásio. }\end{array}$ & 1 & 5 & 2,91 & 1,53 \\
\hline Reúno meus familiares para assistir aos jogos do meu time de basquete. & 1 & 5 & 3,28 & 1,23 \\
\hline $\begin{array}{l}\text { Minha família influencia, de alguma forma, para que eu acompanhe meu time da } \\
\text { NBB. }\end{array}$ & 1 & 5 & 2,41 & 1,39 \\
\hline $\begin{array}{l}\text { Acompanho o basquete, pois minha família me incentiva a buscar novas } \\
\text { experiências esportivas. }\end{array}$ & 1 & 5 & 2,53 & 1,38 \\
\hline Sou sócio de algum clube que participa do NBB. & 1 & 5 & 1,93 & 1,35 \\
\hline Sempre opino em canais de comunicação do meu time de basquete. & 1 & 5 & 2,68 & 1,48 \\
\hline Pagaria para obter os melhores assentos dentro do ginásio nos jogos da NBB. & 1 & 5 & 3,32 & 1,32 \\
\hline $\begin{array}{l}\text { Sempre compro materiais esportivos do meu time de basquete, como camisetas, } \\
\text { bandeiras, chaveiros etc. }\end{array}$ & 1 & 5 & 2,74 & 1,36 \\
\hline Sempre torci para o mesmo time de basquete na NBB. & 1 & 5 & 3,74 & 1,46 \\
\hline Sempre torci para o mesmo time de basquete na NBA. & 1 & 5 & 3,16 & 146 \\
\hline Participarei de eventos que envolvam o NBB, sempre que convidado. & 1 & 5 & 4,03 & 0,96 \\
\hline Acompanho a modalidade, pois me identifico com os valores do basquete. & 1 & 5 & 4,20 & 0,76 \\
\hline $\begin{array}{l}\text { Iria a mais jogos se fossem oferecidas opçôes de entretenimento (como shows, } \\
\text { sorteios, brincadeiras etc.). }\end{array}$ & 1 & 5 & 3,75 & 1,36 \\
\hline
\end{tabular}




\section{Discussão}

Os 91 questionários mostram que o torcedor gosta de participar de eventos esportivos de qualquer modalidade em sua cidade, compareceria a eventos do NBB sempre que convidado, costuma assistir a jogos de basquete com os amigos $(4,10)$ e acompanha a modalidade pois se identifica com os valores do basquete $(4,21)$. A sentença "torço para um time do NBB e sempre vou ao ginásio para vê-lo jogar" registrou média de 3,61. Portanto, há uma identificação das pessoas com as equipes. Cabe aqui a ressalva de que esse número poderia ser maior se as partidas tivessem sido disputadas no ginásio do Paulistano e no ginásio do Bauru. No jogo final, realizado em Araraquara (a cerca de $130 \mathrm{~km}$ de Bauru), observaram-se caravanas de torcedores do Bauru.

Embora exista esse envolvimento afetivo com o basquete e com os times - as conexóes ${ }^{15}$-, a pesquisa indica que os torcedores presentes nos ginásios não investem em uma relação formal ou dispendiosa com as equipes. A média, sempre de um a cinco pontos, para "contribuo com doaçóes, incentivos fiscais, incentivos financeiros, materiais etc. para o meu time de basquete" foi de 1,91; a média para "sempre participo de atividades ligadas a um fä-clube do meu time de basquete" foi de 1,98; a média para "sempre compro materiais esportivos do meu time de basquete, como camisetas, bandeiras, chaveiros etc." ficou em 2,74. Esses dados indicam que os torcedores entrevistados, em sua grande maioria, não se sentem engajados e/ou envolvidos pelas estratégias mercadológicas desenvolvidas pelas equipes participantes da série final (os playoffs) e pela Liga Nacional de Basquete.

Questionado sobre o que a Liga e os clubes têm feito para atrair torcedores para uma relação formal, Guilherme Buso, Gerente de Comunicação da LNB, comentou que algumas equipes oferecem planos para sócio-torcedor, casos do Bauru e do Franca Basquetebol Clube (Franca). Cada vez mais frequentes nos principais clubes de futebol do Brasil, esses programas, em geral relacionados à fidelidade entre torcedor e equipe, oferecem benefícios, como descontos e prioridade na compra de ingressos online, descontos para levar acompanhantes aos jogos, experiências exclusivas (participação em eventos, contato com jogadores etc.), benefícios na rede de parceiros dos times, dentre outros. O torcedor precisa pagar mensalidades ou anuidades para se tornar sócio-torcedor.

Entretanto, a pesquisa aponta que a média para a afirmaçâo "sou sócio de algum clube que participa do NBB” ficou em 1,93. Portanto, esse programa de sócio-torcedor do Bauru precisa ser melhor planejado e divulgado para atingir um maior número de torcedores. O público entrevistado ainda náo consegue enxergar vantagens para aderir à um programa de sócio-torcedor desenvolvido pelas entidades participantes da série final da NBB.

Em relaçáo ao licenciamento de produtos oficiais, o Gerente de Comunicação da LNB disse que já houve uma tentativa, quando a Globo Marcas, que licencia produtos da Globo, comercializou uma linha de produtos do NBB. O resultado, porém, foi insatisfatório. Outro obstáculo aparece nas diferenças entre os times que compóem a Liga. O Clube de Regatas Flamengo, o Botafogo Futebol e Regatas e o Clube de Regatas Vasco da Gama, cuja modalidade principal é o futebol, já têm seus fornecedores de material esportivo. Clubes sociais, como o Clube Atlético Paulistano e o Esporte Clube Pinheiros, não necessariamente têm interesse em licenciar suas marcas. "A Liga gostaria de ter a sua linha de produtos, junto com os clubes. Está no nosso radar, mas não é prioridade, e temos dificuldades de avançar em certos pontos"c.

Outro assunto abordado é a comunicação via mídias sociais. A sentença "acompanho meu time do NBB nas redes sociais" registrou média de 4,00. Buso salienta o trabalho que tem sido feito pela Liga nas redes sociais e o incentivo para que as equipes sigam o mesmo caminho. A fanpage do NBB no Facebook $^{48}$ contava com 650 mil seguidores em julho de 2018 - como base de comparação, a Confederação Brasileira de Futebol (CBF) tinha quase 12 milhóes de seguidores no mesmo período.

Além das transmissóes ao vivo no Facebook e no Twitter, o NBB produz e publica vídeos com os melhores lances dos jogos, entrevistas, jogadas marcantes (enterradas, tocos, arremessos etc.), matérias, fotos etc. Vale destacar a produção de conteúdos especiais para ativar a marca de patrocinadores, como os quadros "Cestas Impossíveis Sky" e "Reloginho Sky". No primeiro, realizado durante a temporada 2016/17 do NBB, jogadores das 15 equipes foram desafiados a elaborar arremessos criativos e diferentes, e os vídeos foram publicados nas mídias sociais do NBB. O quadro se estendeu aos torcedores em forma de promoçáo comercial: entre fevereiro e março de 2017, os fấs de basquete podiam filmar as suas próprias jogadas e publicar no Instagram, com a hashtag \#CestasImpossíveisSKY, para participar de um concurso e concorrer a um prêmio no valor de aproximadamente $\mathrm{R} \$ 4,5 \mathrm{mil}^{49}$. Na temporada 
2017/18, foi lançado o "Reloginho Sky", uma nova disputa entre os jogadores das 15 equipes participantes. Cada time foi representado por uma dupla, que tinha que fazer cestas de 3 pontos no menor tempo possívelos vídeos também foram veiculados nas mídias sociais. As duas duplas finalistas disputaram o título do desafio durante o Jogo das Estrelas de $2018^{50}$. São ações de ativação das marcas dos patrocinadores da LNB.

Para estimular clubes e atletas do NBB a adotarem estratégias bem sucedidas nas mídias sociais, a LNB organiza encontros nos quais profissionais de gestão e de comunicaçáo repercutem cases nacionais e internacionais, promovendo a geração de conhecimento entre todos os agentes envolvidos no universo da liga. O NBB MKT Summit ocorre desde 2015 e conta com a presença de dirigentes de clubes, patrocinadores, jornalistas e pesquisadores na plateia. Em 2017, um dos painéis teve como tema a criação de conteúdo para as diversas plataformas de mídia, na presença de executivos do Facebook, Twitter e do Grupo Globo. Em outro painel, Adam Honig, executivo da MVP Index, empresa norte-americana especializada em mensuração e precificação do retorno das marcas nas mídias digitais e redes sociais, mostrou que a NBA teve o maior crescimento nos esportes profissionais nos Estados Unidos, com 34\% de aumento de engajamento nas redes sociais de 2015 para 2016. Honig descreveu as melhores práticas para Facebook, Twitter e Instagram ${ }^{51}$.

A LNB fechou uma parceria com a MVP Index, para analisar o comportamento dos fấs brasileiros na web, por meio de números e métricas. $\mathrm{O}$ intuito é melhorar os resultados e ampliar o engajamento nas redes sociais do NBB, além de fortalecer a ativação dos patrocinadores, por meio de conteúdos pagos para valorizar suas marcas.

\footnotetext{
A Liga entendeu mais rápido do que os clubes a importância das mídias sociais para produção de conteúdo. Tem sido nosso diferencial, não só para oferecer experiências melhores aos fắs, mas para disponibilizar um conteúdo de qualidade à imprensa. Sportv e Band utilizam o nosso material. O streaming no Facebook e no Twitter ajuda demais, veiculamos dois jogos ao vivo por semana. Tentamos trazer os clubes para o mesmo caminho, por meio de eventos, como o MKT Summit, e reuniōes anuais com as assessorias de imprensa dos times. O Bauru tem feito um excelente trabalho, por exemplo (Entrevista com Guilherme Buso, 2017) $52, \mathrm{~d}$.
}

Os jogadores também são incentivados a usarem as redes sociais como um canal de comunicação. É mais um tópico em que a NBA serve de modelo. Durante o MKT Summit, a MVP Index mostrou que 92\% do EVA (Economic Value Added, o valor agregado) da Nike foi gerado por atletas, sendo o astro do basquete norte-americano Lebron James responsável por 85\% dessa taxa. Lebron inseriu em $95 \%$ dos seus posts uma hashtag da Nike, e essa campanha foi considerada a de melhor retorno na história da NBA nas mídias sociais, de acordo com a MVP Index. Posts sobre bastidores dos jogos e treinos, sobre ações sociais e o dia a dia do ídolo também registram altos índices de engajamento, fortalecendo a conexão do público com a modalidade e tudo que a cerca ${ }^{53}$.

Outro item abordado no questionário aplicado junto aos torcedores foi: "iria a mais jogos se fossem oferecidas opçóes de entretenimento (como shows, sorteios, brincadeiras etc.)". As respostas atingiram a média de 3,76. Transformar as partidas de basquete em eventos de entretenimento é um dos principais objetivos da Liga. O modelo vem de diversos campeonatos mundo afora, que promovem o Match Day destinado aos torcedores, com brincadeiras, venda de produtos com a marca do clube, apresentaçóes de dança, ativações de patrocínio etc. $\mathrm{O}$ envolvimento provocado pelo entretenimento, além de ampliar o público, atraindo famílias e amigos, pode aumentar a conexão do torcedor/consumidor com o produto basquete brasileiro. A sentença "costumo assistir aos jogos do meu time de basquete com meus amigos" atingiu média de 4,10, enquanto "reúno meus familiares para assistir aos jogos do meu time de basquete" registrou 3,28.

A gestão do NBB em variados setores, como comunicação e organização dos eventos, conta com o apoio da NBA, liga independente formada pelos times profissionais de basquete dos Estados Unidos. A parceria teve início em dezembro de 2014. O intuito da NBA ao oferecer consultoria à LNB é contribuir para o fortalecimento da modalidade no país, mercado de consumo importante para o basquete norte-americano ${ }^{4}$ - o Brasil foi o quarto país que mais comentou pelo Twitter a temporada 2016/17 da $\mathrm{NBA}^{53}$. A afirmação "acompanho NBA e gosto de basquete. Por isso, passei a ver os jogos da NBB" registrou média de 3,32.

Guilherme Buso diz que os dirigentes da NBA entendem que, para o basquete brasileiro evoluir, o NBB precisa ser forte, e esse é o caminho para aperfeiçoar a cultura da modalidade no país, angariando mais fās também para a NBA.

A parceria tem sido uma experiência muito boa, dentro e fora de quadra. Times do NBB foram jogar nos Estados Unidos, e profissionais da NBA vieram ao Brasil oferecer 
clínicas. Há esse intercâmbio também para os dirigentes. $\mathrm{O}$ verdadeiro basquete quem faz no Brasil é o NBB e a seleção brasileira. É preciso crescer o basquete como um estilo de vida, não apenas dentro do nicho do 'basqueteiro', e os resultados têm sido positivos também para a NBA (Entrevista com Guilherme Buso, 2017) ) $2, \mathrm{e}^{\mathrm{s}}$

A LNB repassa para os clubes o conhecimento adquirido graças à parceria com a NBA. Os norteamericanos oferecem aos brasileiros o know-how de como entreter o público antes dos jogos e durante os intervalos. Nas duas partidas em que os questionários foram aplicados, observamos atrações nas quadras, como exibições de ginástica artística (patrocínio da Caixa) e brincadeiras com torcedores promovidas pela Sky e pela Avianca. Além disso, o serviço de som do ginásio executa músicas (similares às dos jogos da NBA), um locutor incentiva os torcedores a apoiar o time da casa e os mascotes oficiais das equipes dão um espetáculo à parte, entretendo em especial às crianças, futuros torcedores/consumidores da modalidade.

Guilherme Buso pontua que o orçamento não permite aos executivos da LNB a realização de um trabalho intensivo com os dirigentes dos clubes, para transmitir o know-how adquirido junto aos especialistas da NBA.

Temos em mente uma série de iniciativas para fazer. Uma delas é aperfeiçoar a experiência dentro do ginásio. A NBA nos disponibilizou um dossiê de boas práticas no intervalo, e fizemos um workshop de mascotes durante o Jogo das Estrelas. Tem time que abraçou a ideia, caso do Minas Tênis Clube, enquanto outros olharam e deixaram de lado. Não há uma exigência para que sejam oferecidas atraçốes durante o pré-jogo, o intervalo e o pós-jogo. A Liga não consegue atuar em certos pontos, mas procura estimular durante eventos de marketing, na presença de dirigentes e patrocinadores. Estimulamos, mas depende da iniciativa dos times (Entrevista com Guilherme Buso, 2017) $52, \mathrm{f}$.

As instalaçóes e a estrutura dos ginásios em que ocorrem os jogos do NBB são mais um obstáculo, pois não contribuem para que os organizadores promovam um evento similar aos jogos da NBA. A distância em termos de qualidade do produto NBB para o produto NBA ainda é gigantesca.

O desenvolvimento de estruturas organizacionais bem sucedidas em outros países, como acontece com as ligas profissionais dos esportes norte-americanos, caso da NBA, devem ser estudadas para uma possível adaptação, respeitando as particularidades no esporte brasileiro. A grande vantagem da estrutura organizacional em modelo de liga é que os clubes são os donos da entidade. Com isso, em sua administração, procuram desenvolver açóes e estratégias que beneficiam os próprios clubes. Esse fato pode não acontecer quando os interesses dos clubes são gerenciados por uma Federação e/ou Confederação, dirigida, geralmente, por um burocrata que se perpetua no poder em razão de benefícios e vantagens políticas, e não esportivas. ALNB é um claro exemplo disso. Com os clubes no comando, buscando os próprios interesses e o benefício de todos, a gestáo é mais profissional, alicerçada em conceitos como os de eficiência, eficácia, inovação e criatividade.

Outro aspecto que, acreditamos, precisa ser discutido no Brasil é o modelo de gestão das entidades esportivas, confederações, federaçóes e clubes. O modelo de associaçóes privadas sem fins lucrativos, historicamente adotado pela maioria dos clubes esportivos, favorece a gestão amadora e pouco profissional.

Nos Estados Unidos, as ligas profissionais de basquete, futebol americano, beisebol e hóquei no gelo são empresas privadas, com suas franquias; na Inglaterra, os clubes de futebol são organizaçóes privadas; na Espanha, o modelo associativo de Barcelona e Real Madrid conseguiu equilibrar os interesses dos sócios com uma profunda profissionalização do negócio futebol. Para o fortalecimento da indústria do esporte no Brasil, o modelo atual de propriedade, e consequentemente de gestão, precisa ser repensado, e isso inclui os times de basquete.

$\mathrm{O}$ atual modelo de gestáo preponderante nas organizaçóes esportivas brasileiras, o de entidades associativas de direito privado sem fins lucrativos, estimula o amadorismo na gestão, por evidenciar a formação de grupos políticos para a subida ao poder, em detrimento de critérios profissionais de gestão. Além disso, o mandato de um presidente nesse tipo de entidade, de maneira geral, não estimula a utilização de ferramentas gerenciais modernas. Um bom planejamento estratégico organizacional é elaborado, em organizaçóes empresariais de vanguarda, para um período de, no mínimo, cinco anos. A implantação de tal ferramenta em uma entidade associativa esportiva brasileira é praticamente impossível, uma vez que o período médio de um mandato presidencial, em tal tipo de associação, é de três anos, em média.

É importante salientar que o NBB não está revolucionando a gestão do esporte no Brasil. Também não se pode deixar de citar as dificuldades financeiras que atingem o basquete brasileiro - não só o basquete, mas todo o desporto nacional, reflexo 
de sua má gestão e da crise econômica que assola o país. Há casos de times que participaram do NBB, porém não conseguiram se sustentar e tiveram de fechar as portas, casos das equipes do Instituto Viver Basquetebol, o Brasília (tricampeáo do NBB), e da Associação Limeirense de Basquete, o Winner Limeira (semifinalista na edição de 2016/17).

As agremiaçóes precisam melhorar suas condiçóes de competitividade financeira e econômica. A franquia de Brasília precisava apresentar garantias financeiras na ordem de R \$ 1,5 milhão para seguir no NBB e tentou viabilizar esse valor por meio de patrocínio, mas não conseguiu. Anteriormente, outro patrocinador anunciou que deixaria de apoiar com o valor de $\mathrm{R} \$$ 1,4 milhão por temporada ${ }^{53}$.

Rein, Kotler e Shields ${ }^{15}$ pontuam que os fẫs são conquistáveis se tiverem estímulos adequados. "Nesta era do Torcedor Inconstante, os segmentos do mercado precisam estar bem dimensionados, a fim de se conectar com um mercado de fã̃s em constante mudança"(p. 66) ${ }^{15}$. Num mundo onde as novas tecnologias de comunicação encurtam e globalizam o mercado e há uma aproximação das indústrias do esporte e do entretenimento, a concorrência vem de todos os lados. No caso do NBB, é preciso atrair o admirador de basquete, que tem à sua disposição na TV fechada e na Internet um produto muito melhor, que é a NBA. Há um outro tipo de público, que aprecia o esporte como um todo e eventos de entretenimento. Os executivos do NBB e dos clubes de basquete têm a obrigação de dialogar com esses diferentes tipos de consumidores, para construir um produto que os agrade.

Estudos internacionais sobre o comportamento do consumidor no esporte servem como referência. Dionísio, Leal e Moutinho ${ }^{54}$ avaliam o nível de comprometimento (commitment) e de identificação de torcedores ao Sporting Clube de Portugal no futebol, e ressaltam a importância desse trabalho para profissionais do marketing esportivo. Os pesquisadores diferenciam os torcedores em participantes (sócios que pagam mensalidade e usam camisa e outros produtos do clube) e os extremamente fanáticos, membros que adotam o símbolo da torcida organizada. O comportamento associativo do fâ de futebol é influenciado pelo desejo de reconhecimento social, socialização e simbolismo. A pesquisa mostra que existe resistência por parte de torcedores em relação aos patrocinadores que usam o clube para expor suas marcas. Porém, o dinheiro investido por essas empresas é fundamental para o fortalecimento das equipes. Os autores recomendam que os clubes desenvolvam uma estratégia educacional para explicar aos torcedores os benefícios e mostrar que os parceiros ajudam o clube a contratar jogadores para aumentar a competitividade do time. O patrocinador precisa investir em um relacionamento longo com o clube e com os torcedores para mostrar um envolvimento emocional, além de investir em outras modalidades, e não apenas o futebol ${ }^{54}$.

Esse conhecimento pode ser aplicado no cenário do basquete brasileiro. Identificar os conectores que unem o fă, o torcedor, ao produto basquete brasileiro de clubes é fundamental para que os gestores da LNB e dos clubes tracem estratégias de sucesso para o constante crescimento da entidade. Esta pesquisa demonstrou, com seus resultados, que o caminho passa pelo entretenimento e pelas estratégias de comunicação já iniciadas pela Liga e que podem, de forma melhor planejada, aumentar a ligação entre o torcedor e o basquete brasileiro.

É nossa intenção, através da análise do trabalho realizado pela $\mathrm{LNB}$, contribuir para a melhoria do processo de gestão e de comunicação das entidades esportivas do Brasil. Um fator limitante da pesquisa foi o número de respostas obtidas para os questionários. Cabe ressaltar que os dois jogos não foram disputados nos ginásios das equipes mandantes. Além disso, o público que frequenta as finais pode ser diferente daquele que comparece aos jogos da primeira fase. Portanto, esse estudo de caso não deve ser generalizado, e novos questionários podem ser aplicados em outros jogos, cidades e estados, para ampliar a pesquisa.

\section{Notas}

a. Citado por Van Rossum JHA. Perceptions factors of determining in athletic achievement: an addendum to Hyllegard, et al. Perceptual Motor Skills. 2004;98:81-555.

b. A Brand Finance explica que o ingrediente mais importante para o Manchester United possuir a marca mais valiosa do mundo é a capacidade comercial do clube e a habilidade para obter lucro em acordos com dezenas de empresas e em diversos países.

c. Guilherme Buso em entrevista ao autor, concedida em dezembro de 2017. 
d. Guilherme Buso em entrevista ao autor, concedida em dezembro de 2017.

e. Guilherme Buso em entrevista ao autor, concedida em dezembro de 2017.

f. Guilherme Buso em entrevista ao autor, concedida em dezembro de 2017.

\section{Abstract}

The sports consumer and the New Basketball Brazil (NBB): analysis of fan profile in 2016-17 finals games.

This articleaimsto study the connections between basketball and itsfans and to analyzethe profile of sports fans that attended the two last finals games of the NBB (New Basketball Brazil, the main men's Brazilian tournament), in its ninth edition, in 2017. We conducted a qualitative study: 39 questions were answered by fans chosen randomly before the game, inside and around the arenas. The two games occurred in São Paulo and Araraquara, cities of São Paulo State, in 2017. We analyzed 91 questionnaires and observed the sponsorship activations during the events. The results were the base to a semi-structured interview with Marketing and Communications Manager at Brazil's National Basketball League (LNB). The results indicate the predominance of a male, young and high purchasing power ( $57 \%$ of respondents havea monthly family income above $R \$ 4,500$ ) attendance in the arenas. These fans present a high affective involvement with basketballand theirteams, buttheydon'thavea monetaryinvolvement, becausetheydon'tspend moneyto benefittheclubs. The communication by social media reaches a high proportion of the publicthat answered the questionnaire, and these fans approve entertainment actions during sports events. Therefore, the NBB and Brazilian professional basketball teams could improve their relationship with the fans. The LNB has adopted successful practices abroad in sport management since 2008 and has achieved partnerships with big companies and communications groups. In addition, the League announced in 2014 a groundbreaking multiyear partnership with National Basketball Association (NBA). There are still management deficiencies to be overcome in Brazilian basketball teams, and this paper intends to contribute to this process.

KEYWORDs: Communication; Sport Management; Marketing; NBB; Brazil's National Basketball League.

\section{Referências}

1. Mazzei LC, Rocco Júnior AJ. Um ensaio sobre a Gestấo do Esporte: um momento para a sua afirmaçáo no Brasil. Rev Gestão Negócios Esporte. 2017;2(1):96-109.

2. Liga Nacional de Basquete. Disposiçóes Estatutárias. São Paulo: LNB; 2016.

3. Malagrino FAF. O torcedor como vantagem competitiva: uma análise sob a ótica da transferência da lealdade [tese]. São Paulo: Universidade de São Paulo, Faculdade de Economia, Administração e Contabilidade; 2017.

4. Dietl HM, Franck EP, Hasan T, Lang M. Governance of Professional Sports Leagues: cooperatives versus contracts. Int Rev Law Economics. 2009;29(2):127-137.

5. Hansen H, Gauthier R. Factors affecting attendance at professional sport events. J Sport Management. 1989;3(1):15-32. 6. Biscaia R, Hedlund DP, Dickson G, Naylor M. Conceptualising and measuring fan identity using stakeholder theory, Eur Sport Management Quarterly. 2018;18(4):459-481.

7. McCarthy J, Rowley J, Ashworth C, Pioch E. Managing brand presence through social media: the case of UK football clubs. Internet Res. 2014;24(2):181-204.

8. Robinson MJ, Trail GT, Dick RJ, Gillentine AJ. Fans vs spectators: an analysis of those who attend intercollegiate football games. Sport Marketing Quarterly. 2005;14(1):43-53.

9. Dixon K. Consuming Football in Late Modern Life. Ashgate Publishing: Aldershot; 2013.

10. Foer F. How Soccer Explains the World: An Unlikely Theory of Globalization. HarperCollins Publishers: New York; 2010. 11. Kennedy P, Kennedy D. Football supporters and the commercialisation of football: comparative responses across Europe. Soccer Soc. 2012;13(3):327-340.

Rev Bras Educ Fís Esporte, (São Paulo) 2021 Jul-Set;35(3):51-65 • 63 
12. Hedlund DP. Creating value through membership and participation in sport fan consumption communities. Eur Sport Management Quarterly. 2014;14(1):50-71.

13. McDonald H, Karg AJ, Vocino A. Measuring season ticket holder satisfaction: rationale, scale development and longitudinal validation. Sport Management Rev. 2013;16(1):41-53.

14. Ioakimidis M. Online marketing of professional sports clubs: engaging fans on a new playing field. Int J Sports Marketing Sponsorship. 2010;11(4):271-282.

15. Rein I, Kotler P, Shields B. Marketing Esportivo: a reinvenção do esporte na busca de torcedores. Porto Alegre: Bookman; 2008.

16. Brasil. Lei no 10.671. Dispóe sobre o Estatuto de Defesa do Torcedor e dá outras providências. Diário Oficial. República Federativa do Brasil [Internet]; 2003. Disponível em: http://www.planalto.gov.br/ccivil_03/leis/2003/110.671.htm.

17. Farias AMLD, Laurence LDC. Estatística descritiva. Apostila-Universidade Federal Fluminense. Rio de Janeiro. 2006; $128 \mathrm{f}$.

18. Creswell JW. Projeto de pesquisa: métodos qualitativo, quantitativo e misto. 2. ed. Porto Alegre: Artemed; 2007.

19. Edwards A, Skinner J. Qualitative research in Sport Management. Oxon: Butterworth-Heinemann; 2009.

20. Bardin L. Análise de conteúdo. 5a ed. Lisboa: Ediçôes 70; 2013.

21. Moraes R. Análise de conteúdo. Rev Educação. 1999;22(37):7-32.

22. Barthes R. O que é o Esporte? Rev Serrote São Paulo. 2009;3:97-105.

23. Campos AG, Rocco Júnior AJ. O Esporte e o Mundo Contemporâneo: por uma defesa da Comunicação como principal valor estratégico para a gestão de organizações e produtos esportivos. Rev Communicare. Casper Líbero. 2014;14:124-139.

24. Bourdieu P. Sobre a televisão. Rio de Janeiro: Jorge Zahar Editor; 1997.

25. Jenkins H. Cultura da convergência. 2a edição. São Paulo: Aleph; 2009.

26. Hudson S, Huang L, Roth MS, Madden TJ. The influence of social media interactions on consumerbrand relationships: a three-country study of brand perceptions and marketing behaviors. Int J Res Marketing. 2016;33(1):27-41.

27. Neff J. Digital is selling more soap that it gets credit for: Nielsen study. Advertising Age. 2014;20:1-2.

28. Berger J, Milkman KL. What makes online content viral? J Marketing Res. 2012;49(4):192-205.

29. Chanavat N, Bodet G. Internationalization and sport branding strategy: a French perception of the Big Four brands. Qualitative Market Res Int J. 2009;12(4):460-481.

30. Ambler T. How much of brand equity is explained by trust?. Management Decision. 1997;35(3/4):283-292.

31. Fournier S. A consumer-brand relationship framework for strategic brand management. Doctoral dissertation, Florida, University of Florida; 1994.

32. Drigotas SM, Rusbult CE. Should I stay or should I go? A dependence model of breakups. J Personality Social Psychol 1992;62(1):62-87.

33. Veloutsou C. Identifying the dimensions of the product-brand and consumer relationship. J Marketing Management. 2007;23(1/2):7-26.

34. Ahn T, Hong M, Pedersen PM. Effects of perceived interactivity and web organization on user attitudes. Eur Sport Management Quarterly. 2014;14(2):111-128.

35. Anisimova TA. The effects of corporate brand attributes on attitudinal and behavioral consumer loyalty. J Consumer Marketing. 2007;24(7):395-405.

36. Alloza A. Brand engagement and brand experience at BBVA, the transformation of a 150 years old company. Corp Reputation Rev. 2008;11(4):371-379.

37. Vivek SD, Beatty SE, Morgan RM. Customer engagement: Exploring customer relationships beyond purchase. J Marketing Theor Pract. 2012;20(2):122-146.

38. Warrington P, Shim S. An empirical investigation of the relationship between product involvement and brand commitment. Psychol Marketing. 2000;17(9):761-782.

39. O' Loughlin D, Szmigin I, Turnbull P. From relationships to experiences in retail financial services. International Journal of Bank Marketing. 2004; 22(7):522-539.

40. Sreejesh S. Consumers' Perceived brand aspiration and its impact on intention to pay price premium: moderating role of brand jealousy. Theor Economics Lett. 2014;5(2):273-284.

41. Meira TB, Bastos FC, Böhme MTS. Análise da estrutura organizacional do esporte de rendimento no Brasil: um estudo preliminar. Rev Bras Educ Fís Esporte. São Paulo. 2012;26:251-262.

42. Brasil. Lei no 9.615. Institui normas gerais sobre desporto e dá outras providências. Diário Oficial. República Federativa 
do Brasil [Internet]; 1998. Available from: https://goo.gl/PxMMJU.

43. Globoesporte.com. E agora? Como fica o esporte olímpico brasileiro após a Rio 2016? [Internet]. Rio de Janeiro: Globoesporte.com; 2017. Disponível em: https://goo.gl/wZCLFa.

44. Brand Finance. Brand Finance Football 502017 - The annual report on the most valuable football brands. [Internet]; June 2017. Disponível em: https://goo.gl/1QwNJz.

45. Brand Finance. Brand Finance Football 502015 - The annual report on the world's most valuable football brands. [Internet]; June 2015. Disponível: https://goo.gl/iGUCFi.

46. Brand Finance. Brand Finance Football 502016 - The annual report on the world's most valuable football brands. [Internet]; June 2016. Disponível em: https://goo.gl/WTDPY6.

47. Oliveira N. Brasileiro teve rendimento domiciliar per capita de R\$ 1.226 no ano passado. Rio de Janeiro: EBC; 2017. Disponível em: https://goo.gl/zeTCBv.

48. Facebook. Página oficial do NBB [Internet]. Disponível em: https://www.facebook.com/NBB/. Acesso em: jul 2018. 49. Sky. Regulamento da promoção comercial Cestas Impossíveis Sky [Internet]. Disponível em: https://goo.gl/bsaVqj. Acesso em: jul 2018.

50. Balassiano F. Sábado do Jogo das Estrelas terá atraçôes durante todo dia no Ibirapurea. UOL [Internet]; 2018. Disponível em: https://goo.gl/ZuFwV8.

51. Honing A. Social Media: measurement \& valuation. $3^{\circ}$ NBB MKT Summit; 5-set 2017; São Paulo, BR.

52. Leister Filho A. Brasil é o $4^{\circ}$ país que mais comentou NBA pelo Twitter. São Paulo: Máquina do Esporte [Internet]; 2017. Disponível em: https://goo.gl/RYPuLu.

53. Ferraz I, Rodrigues L. Brasília não terá representante na liga de basquete (NBB) em 2017. Brasília: Metrópoles [Internet]; 2017. Disponível em: https://goo.gl/Gishkq.

54. Dionísio P, Leal C, Moutinho L. Fandom affiliation and tribal behaviour: a sports marketing application. Qualitative Market Res Int J. 2008;11(1):17-39.

55. Van Rossum JHA. Perceptions factors of determining in athletic achievement: an addendum to Hyllegard, et al. Perceptual Motor Skills. 2004;98:81-5

\begin{tabular}{r|r} 
ENDEREÇo & \\
Ary José Rocco Junior & \\
Escola de Educação Física e Esporte & Submetido: 18/07/2018 \\
Universidade de São Paulo & 1a. Revisão: 20/01/2019 \\
Av. Prof. Mello Moraes, 65 - Cidade Universitária & 2a. Revisão: 14/06/2019 \\
O5508-030 - São Paulo - SP - Brasil & Aceito: 26/10/2021 \\
E-mail: aryrocco@usp.br & \\
&
\end{tabular}

